\title{
APLICAÇÕES EDUCACIONAIS EM 3D PARA OS PROCESSOS DE ENSINO E APRENDIZAGEM DA ÁREA DE ANATOMIA NO SECOND LIFE
}

\author{
Giselle Massaro - Unilasalle - gisellemassaro@gmail.com \\ Ana Margô Mantovani - Unilasalle - margo@unilasalle.edu.br \\ Marcello da Silva Rodrigues - Unilasalle - marcello@unilasalle.edu.br
}

Resumo: Este artigo apresenta a construção de aplicações educacionais em 3D com o uso do Metaverso Second Life no contexto da Ilha RICESU. Construiu-se um Laboratório de Anatomia em 3D, contextualizado com material didático-pedagógico para ser utilizado como apoio na $\mathrm{EaD}$ e na educação presencial. Através dos extratos de análise, oriundos dos registros no próprio ambiente e questionários, constatou-se que as aplicações desenvolvidas podem auxiliar nos processos de ensino e aprendizagem da área de Anatomia, por favorecer a aprendizagem através de recursos pedagógicos flexíveis e personalizáveis, tais como objetos, animações e simulações, em um ambiente que possibilita um alto grau de imersão e de interação entre alunos, professores e conteúdos/contexto, enriquecendo as práticas formativas e educativas.

Palavras-chave: Educação a Distância. MDV3D. Second Life. Anatomia.

\section{D EDUCATIONAL APPLICATIONS FOR THE LEARNING AND TEACHING PROCESS OF THE AREA OF ANATOMY IN THE SECOND LIFE}

\begin{abstract}
This article presents the build of 3D educational applications using the Metaverse Second Life in the RICESU island context. 3D Anatomy Laboratory was built in context with didactic-pedagogicals material that may be used as support in the distance and presential education modality. Through extracts of analysis enabled registers in the own environment and questionnaires, it was found that the educational aplications developed can assist in the teaching and learning concepts related to the area of Anatomy, by promoting learning through of pedagogical resources flexibles and customizable, as learning objects, animations and simulations in an environment that enables a high degree of immersion and interaction between students, teachers and content / context, enriching the educational and training practices.
\end{abstract}

Keywords: Distance Education. Digital 3D Virtual World. Second Life. Anatomy.

\section{Introdução}

Com o crescente uso do computador nos ambientes educacionais e a possibilidade de educação a distância $(\mathrm{EaD})$, surge a necessidade de repensar as atuais práticas didático-pedagógicas, tendo em vista as potencialidades que as Tecnologias Digitais Virtuais (TDVs) apresentam para o contexto escolar. Conforme Mattar e Valente (2007, p. 71), a escola que temos hoje muito provavelmente não existirá mais, e a distinção entre $\mathrm{EaD}$ e educação presencial será cada vez menos perceptiva, em função do advento das tecnologias da Web 2.0 e da Web3D, que permitem a interação e o compartilhamento de conhecimento. 
A presença cada vez mais intensa da $\mathrm{EaD}$ nas instituições de ensino, em especial nas instituições de ensino superior, abre novos rumos e possibilidades para a educação. No entanto, para que se consiga atingir os objetivos pretendidos faz-se necessário a utilização de ambientes que agreguem qualidade e dinamismo às aulas. Diante dessa necessidade, pensar em ambientes virtuais de aprendizagem mais atrativos, que permitam maior interação e imersão do aluno, mostra-se indispensável para que o aluno se sinta motivado e entusiasmado a participar das aulas.

Atualmente, as tecnologias da Web3D tais como metaversos - Mundos Digitais Virtuais 3D (MDV3D), permitem a construção de Mundos Virtuais que, vinculados a uma proposta didático-pedagógica, podem contribuir com os processos de ensino $\mathrm{e}$ aprendizagem. As diversas experiências pedagógicas que têm sido realizadas em mundos virtuais, principalmente com o uso do metaverso Second Life (SL), demonstram a importância de criar um espaço de aprendizagem que seja atraente para o aluno.

Nessa perspectiva, foram construídas aplicações educacionais em 3D, utilizando a tecnologia de metaverso Second Life no contexto da Ilha RICESU ${ }^{1}$, para contribuir com os processos de ensino e aprendizagem relacionados aos conceitos da área de Anatomia.

\section{Tecnologias da Web 3D: metaversos - MDV3D}

De acordo com Schlemmer e Backes (2008, p.522) o metaverso é "[...] uma tecnologia que se constitui no ciberespaço e se "materializa" por meio da criação de Mundos Digitais Virtuais em 3D - MDV3D, no qual diferentes espaços para o viver e conviver são representados em 3D." Entre os metaversos mais conhecidos que possibilitam a criação de MDV3D está o Second Life, software que possui características de diferentes ferramentas como jogos, ambientes virtuais, chats, comunidades virtuais, etc.

No contexto educacional, os metaversos - MDV3D apresentam inúmeras possibilidades pedagógicas, caracterizando-se como um importante recurso para apoiar os professores e alunos no processo de ensino e aprendizagem, sendo possível realizar atividades através da utilização de espaços de convivência, simuladores, objetos de aprendizagem, além dos meios de comunicação e interação que o ambiente proporciona.

Outra característica dos metaversos é a possibilidade de integrar diferentes tecnologias da Web 2.0 aos espaços criados no metaverso, agregando recursos pedagógicos que o metaverso não possui. Os metaversos-MDV3D possibilitam novas formas de interação proporcionadas pelo alto grau de imersão do sujeito (e-habitante) no ambiente, pois pode estar telepresente por meio de um avatar, uma representação gráfica em 3D, e interagir através das diferentes linguagens de comunicação: textual (por meio de textos), oral (áudio), gestual (movimentos evidenciados nas ações do avatar) e gráfica (imagens). Nesse aspecto o metaverso-MDV3D resgata a fisicalidade dos AVAs e destaca-se como uma tecnologia indicada para favorecer o envolvimento dos alunos, mostrando-se mais interessante do que apenas o uso de AVAs, tais como Teleduc e Moodle, ${ }^{2}$ uma vez que não encontramos essas características em tais ambientes.

Conforme afirma Mattar (2008, p.6), o SL "possibilita colocar em prática diversas estratégias contemporâneas do design instrucional, como aprendizado distribuído, aprendizado pela descoberta, aprendizado situado, aprendizado ancorado, aprendizado autêntico, aprendizado pelo fazer e aprendizado ativo". Para o autor referido, estamos vivenciando o que podemos chamar de $\mathrm{EaD} 3.0$, com os ambientes tridimensionais oferecendo novas possibilidades de ensino e aprendizagem. 
Para o desenvolvimento de aplicações mais complexas, o $S L$ possui ferramentas avançadas de programação e construção, que possibilitam o desenvolvimento de simulações. As simulações que podem ser realizadas nos seus ambientes estão entre as potencialidades mais relevantes do SL para a educação. E, especificamente, para o estudo de Anatomia, é possível desenvolver um ambiente em que o usuário possa interagir, experimentar e criar situações, o que pode contribuir significativamente para sua aprendizagem. As aplicações que permitem ao usuário realizar experimentos são importantes meios utilizados na aprendizagem, pois dessa forma o usuário pode vivenciar situações que seriam muito dificeis de serem realizadas no mundo físico, tornando o processo de aprendizagem mais prazeroso devido à possibilidade de se interagir com algo que imita a realidade.

\section{O processo de ensino da Anatomia e as Tecnologias Digitais Virtuais (TDVs)}

A disciplina de Anatomia, presente em diversos cursos da área da saúde, visa o estudo teórico-prático da localização, do reconhecimento e da caracterização dos órgãos do corpo humano, dos sistemas cardiovascular, respiratório, muscular e nervoso dentre outros. Estão disponíveis na internet um acervo de imagens, vídeos e artigos que auxiliam e complementam o estudo da Anatomia. Os recursos de multimídia, animações e simulações trazem ao aluno um novo conceito de estudo, permitindo-lhe uma maior interação com o material proposto. Assim, as diversas TDVs tornam-se aliadas no processo de ensino e aprendizagem dos conceitos relacionados à área de Anatomia, possibilitando o desenvolvimento de novas práticas didático-pedagógicas, facilitando a compreensão de assuntos complexos.

As TDVs podem ser aplicadas para integrar o ensino teórico-prático da Anatomia, na tentativa de adequar o ensino à realidade atual, servindo como um subsídio às aulas. No entanto, considera-se importante destacar que, para os especialistas da área, as práticas de laboratório em um espaço físico-presencial ainda não podem ser substituídas pelo uso das diversas tecnologias atuais, pois é um momento em que o aluno tem o contato direto com as peças anatômicas, podendo perceber $\mathrm{e}$ analisar texturas, peso, diâmetro, enfim, todas as características que são perceptíveis pelo contato físico (tato), sendo este tipo de prática ainda considerado fundamental para a compreensão de tais características. Então, tanto o uso das TDVs quanto dos metaversos - MDV3D são tecnologias consideradas complementares às práticas de laboratório (físico-presencial). $\mathrm{Na}$ perspectiva de apresentar alternativas de complemento às práticas de ensino e aprendizagem para área de Anatomia, desenvolveu-se este trabalho, que será detalhado a seguir.

\section{Aplicações educacionais em 3D para os processos de ensino e aprendizagem da área de Anatomia no metaverso Second Life}

Este trabalho originou-se inicialmente a partir do projeto "Anatomia no Second Life: uma proposta em i-Learning" (SCHLEMMER et. al., 2010) que é um projeto de desenvolvimento na área de Immersive Learning vinculado à disciplina de Anatomia, presente em diferentes cursos da graduação. Este projeto está sendo realizado por um grupo interinstitucional e interdisciplinar por instituições que compõem a Ilha RICESU, sendo que a instituição de origem das autoras desse trabalho fazia parte desse grupo. No entanto, por questões institucionais, esse trabalho foi desvinculado de tal projeto.

Desse modo, o objetivo desse trabalho é a construção de aplicações educacionais em 3D, tais como desenvolvimento de objetos de aprendizagem e conteúdos interativos, 
através de animações e simulações, utilizando a tecnologia de Metaverso Second Life no contexto da Ilha RICESU, relacionadas aos conceitos da área de Anatomia, e verificar como essas aplicações podem contribuir para os processos de ensino e aprendizagem nessa área. Assim sendo, constituiu-se uma equipe técnico-didático-pedagógica interdisciplinar composta por um professor da área de Anatomia, uma pedagoga (Mestre em Educação) com atuação na área de Informática na Educação (professora orientadora do trabalho, co-autora) e uma aluna do curso Computação - Licenciatura, autora desse trabalho.

A partir do feedback do professor em relação às dificuldades encontradas pelos alunos nessa disciplina, realizou-se o planejamento didático-pedagógico da disciplina de Anatomia no metaverso Second Life. Foram então definidos os conteúdos/conceitos a serem desenvolvidos no $S L$, bem como os tipos de aplicações educacionais. Tendo em vista que seria o primeiro contato do professor e dos alunos com o metaverso Second Life, optou-se pela representação de um Laboratório de Anatomia em 3D, mas utilizando as características da natureza do meio, que é digital-virtual. Durante esse processo foram realizadas várias reuniões com a equipe para acompanhamento do trabalho, a fim de garantir com o docente da disciplina de Anatomia se as aplicações estavam em conformidade com os conteúdos/conceitos desenvolvidos nessa disciplina.

\subsection{Aplicações Educacionais no Laboratório de Anatomia em 3D}

A seguir apresentam-se as aplicações educacionais desenvolvidas no Laboratório de Anatomia em 3D, contextualizado com material didático-pedagógico para ser utilizado como apoio na $\mathrm{EaD}$ e na educação presencial. Esse ambiente (Figura 1) encontra-se acima do novo Espaço Digital Virtual 3D (EDV3D) da instituição de origem das autoras, situado na Ilha RICESU no metaverso $S L$.

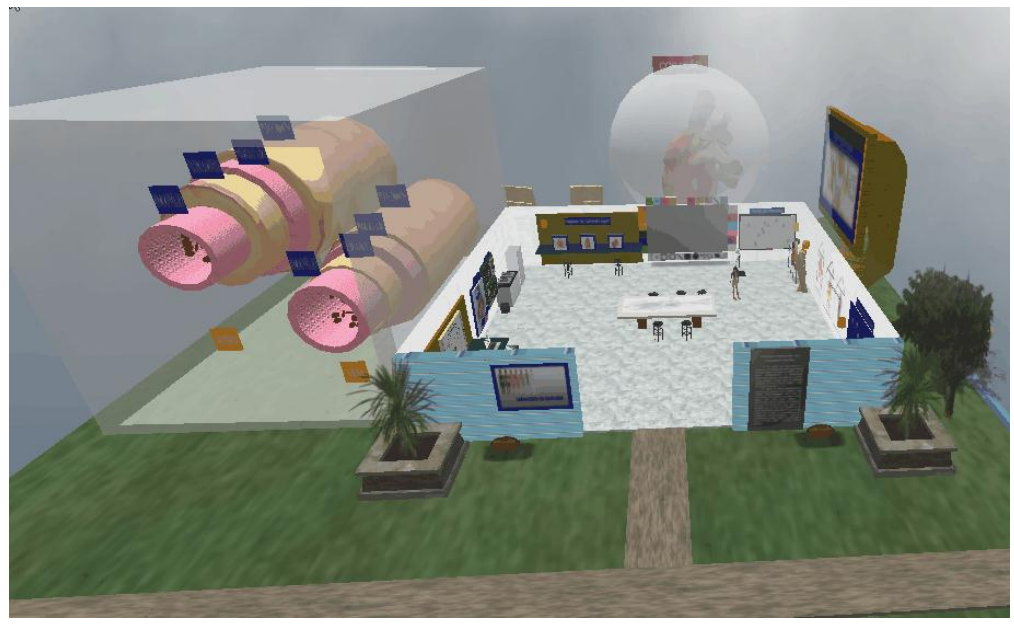

Figura 1 - Laboratório de Anatomia

Fonte: Autoria própria, 2011

O Laboratório de Anatomia contém as seguintes aplicações educacionais:

-Display de slides: Permite ao professor apresentar slides aos alunos (Figura 2).

-Painel para acessar web sites: Trata-se de uma textura de mídias que permite incorporar vídeos e páginas web ao ambiente. Dessa forma, toda informação pode ser acessada dentro do ambiente sem ser necessária a utilização de um navegador web (Figura 3). 


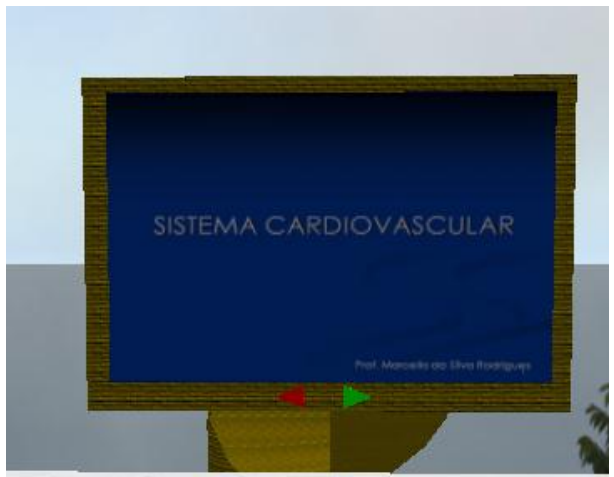

Figura 2 - Display para apresentação de slides Fonte: Autoria própria, 2011

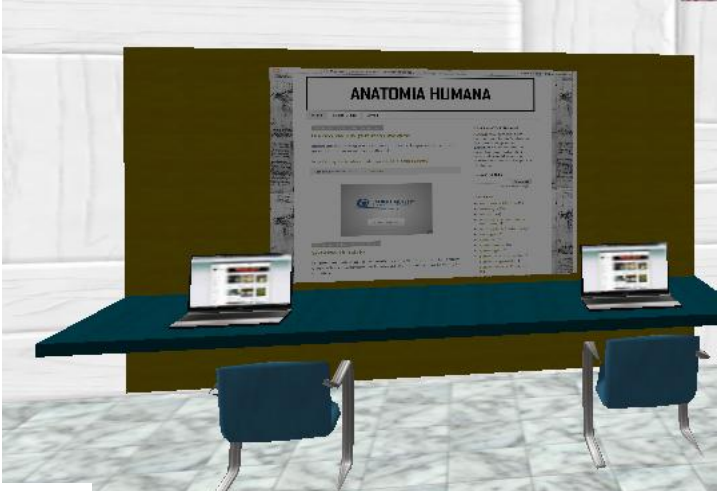

Figura 3 - Painel para web sites Fonte: Autoria própria, 2011

-Painel com links interessantes: O painel foi desenvolvido para que o professor possa compartilhar endereços de páginas web com os alunos, disponibilizando links de páginas web sobre Anatomia que podem ser utilizadas como apoio e complemento as aulas. O painel com links interessantes pode ser visualizado na Figura 4.

-Videoteca: Trata-se de um objeto construído para disponibilizar vídeos que ficarão a disposição para serem assistidos pelos alunos no Laboratório de Anatomia. O professor poderá disponibilizar vídeos de sua autoria ou indicar vídeos disponibilizados em sites como YouTube por exemplo, que julgue interessantes e relevantes a sua disciplina. Os vídeos são tecnologias poderosas para auxiliar no processo de ensino e aprendizagem dos alunos. Pode-se, por exemplo, filmar partes do corpo humano, filmar uma aula da disciplina, e ainda disponibilizar vídeos sobre o assunto, desenvolvidos por outras pessoas, e que estão disponibilizados na internet para que o aluno possa assistir quantas vezes desejar. A videoteca pode ser visualizada na Figura 5.

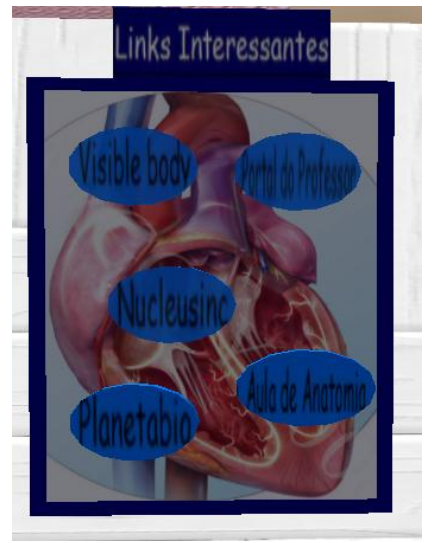

Figura 4 - Painel com links interessantes Fonte: Autoria própria, 2011

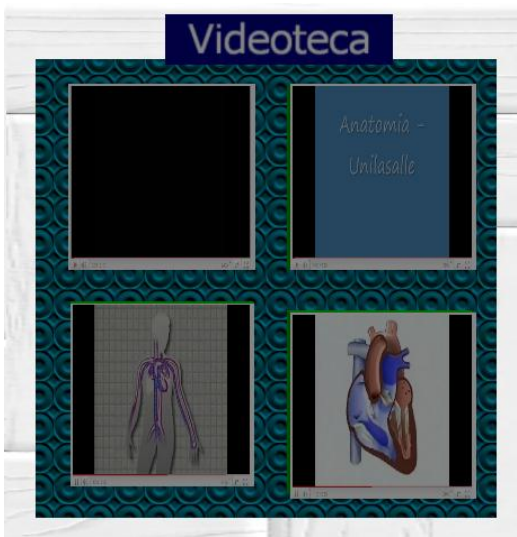

Figura 5 - Videoteca

Fonte: Autoria própria, 2011

-Mural de desafios e Mural de interações: Esses murais são objetos em formato de quadro branco que permitem que os alunos disponibilizem notecards com informações textuais. Esse espaço permite que o professor acompanhe o desenvolvimento do aluno, através da avaliação dos notecards postados, percebendo a interação do aluno com o ambiente. Através do mesmo espaço poderá ser oferecido um feedback ao aluno. 
-Espaço para desafios: $\mathrm{O}$ espaço para desafios foi desenvolvido para o professor disponibilizar atividades em formato de desafios aos alunos. Os desafios são disponibilizados aos alunos no formato de notecard. Ao clicar em um dos discos coloridos, um notecard com a descrição de um desafio é oferecido ao aluno. $\mathrm{O}$ aluno poderá salvar o notecard no seu inventário e acessar sempre que desejar (Figura 6).

-Objetos de aprendizagem: Estão dispostos sobre uma bancada, e possuem um formato de caixa. Cada caixa exibe uma imagem de uma parte do corpo humano (Figura 7). Ao clicar sobre a caixa, ela se expande exibindo a imagem em tamanho maior e ao mesmo tempo são oferecidos ao aluno textos com explicações sobre a imagem que está sendo exibida. Nessa aplicação, o professor poderá disponibilizar informações que poderão além de ser ilustradas por imagens, complementadas por textos.

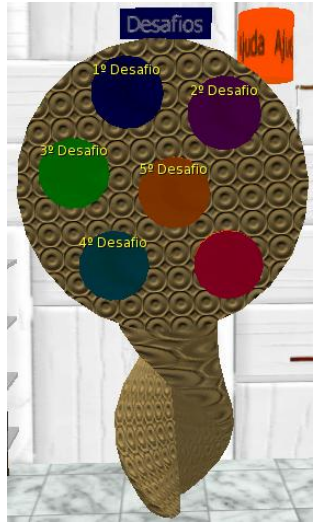

Figura 6 - Espaço para desafios Fonte: Autoria própria, 2011

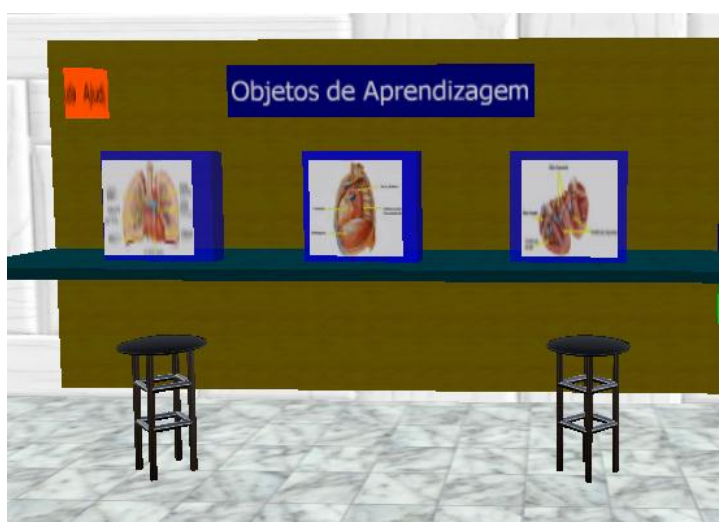

Figura 7 - Objetos de Aprendizagem Fonte: Autoria própria, 2011

-Simulação - Veia e Artéria: Essa simulação foi construída com o objetivo de reproduzir uma veia e uma artéria. Nos objetos construídos foram demonstradas suas composições estruturais, indicando o nome de cada uma das camadas. O propósito dessa simulação (Figura 8) é dar ao aluno a possibilidade de visualizar a diferença estrutural entre veia e artéria.

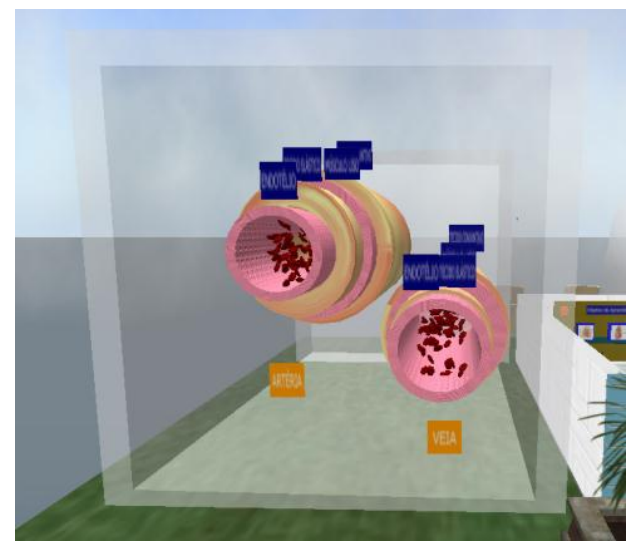

Figura 8 - Simulação veia e artéria

Fonte: Autoria própria, 2011

-Animação - Coração: A animação do coração em 3D foi produzida utilizandose objeto em formato de coração que apresenta o movimento de sístole e diástole. Foi adicionado movimento de rotação para que o aluno não necessitasse se locomover em 
torno do objeto. O objeto apresentado na Figura 9 mostra o coração, que foi acomodado em uma meia esfera transparente. Para que os alunos pudessem responder o desafio proposto para essa animação, o coração foi fotografado de dois ângulos diferentes. Cada estrutura do coração foi numerada em cada uma das imagens que foram dispostas em cavaletes ao lado do coração, conforme apresentado na Figura 10.

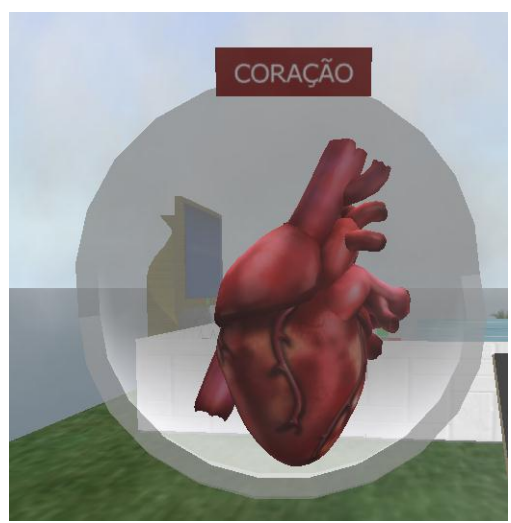

Figura 9 - Animação Coração Fonte: Autoria própria, 2011

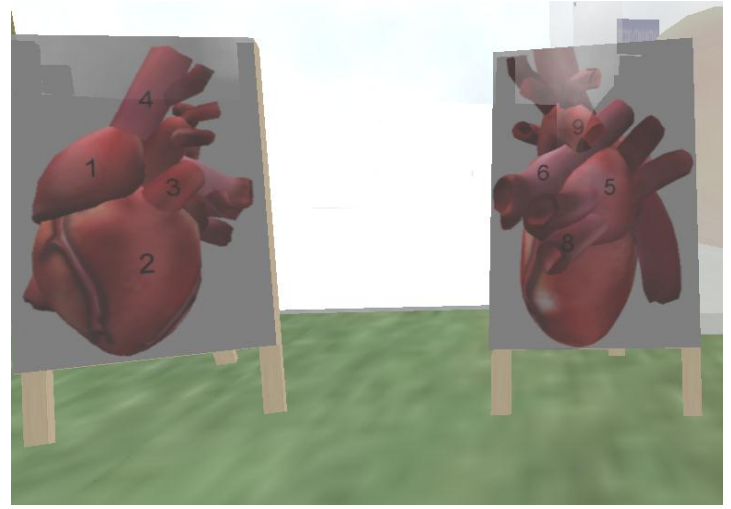

Figura 10 - imagens estáticas e numeradas do coração

Fonte: Autoria própria, 2011

Na Figura 11 apresenta-se um dos desafios propostos a partir da observação dos movimentos e das estruturas numeradas do coração.

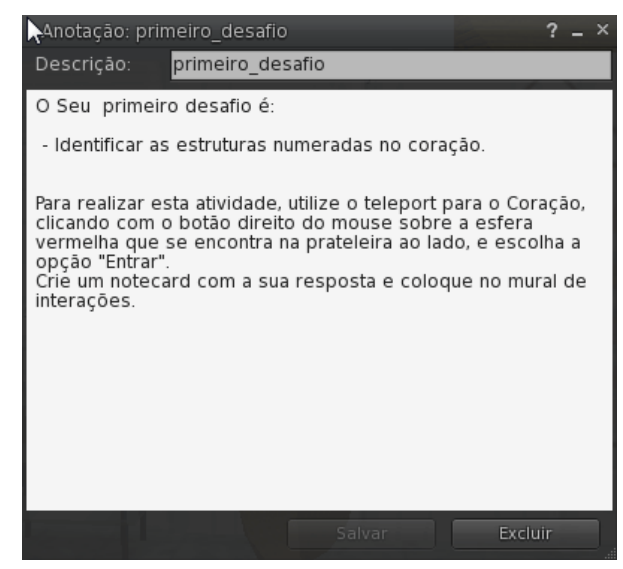

Figura 11 - Exemplo de desafio proposto

Fonte: Autoria própria, 2011

-Simulação - Colesterol: Essa simulação demonstra a parte interna de uma veia, mostrando também as hemácias percorrendo seu interior. Nas paredes das veias estão representadas placas de gordura. O propósito da simulação é demonstrar que as placas de gorduras presentes nas paredes das veias impedem o sangue de circular. Para sair da simulação e retornar ao laboratório, o aluno deverá clicar sobre a esfera azul que se encontra dentro da veia e escolher a opção Sair. $O$ interior da simulação pode ser visualizado na Figura 12. 


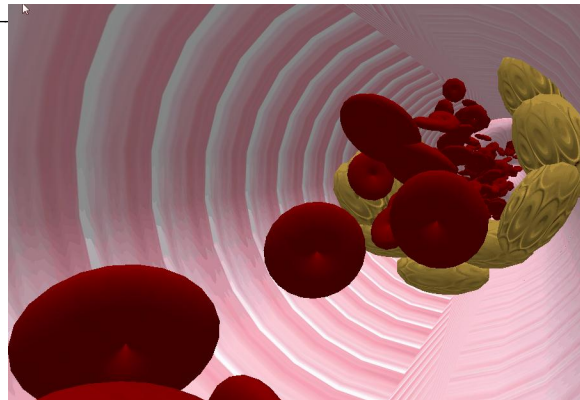

Figura 12 - Interior da simulação Colesterol Fonte: Autoria própria, 2011

As aplicações educacionais construídas no metaverso SL foram avaliadas de forma qualitativa na modalidade presencial, sendo que o campo empírico constitui-se de alunos provenientes do curso de Ciências Biológicas (entre o $2^{\circ}$ e $4^{\circ}$ semestres) que cursam a disciplina de Anatomia na instituição das autoras, com o respectivo professor, integrante da equipe técnico-didático-pedagógica. Foram utilizados como instrumentos de pesquisa dois questionários, cinco desafios em formato de notecard e observações das interações desses alunos com as aplicações educacionais implementadas no Laboratório de Anatomia 3D.

Em relação à exploração do ambiente Laboratório de Anatomia e a interação com as aplicações educacionais em 3D construídas no laboratório, foi possível observar que os sujeitos interagiram com todas as aplicações, demonstrando interesse e entusiasmo em realizar as atividades propostas.

A respeito das possibilidades pedagógicas que percebiam na utilização do metaverso como apoio às disciplinas de Anatomia, e de que forma essas aplicações poderiam auxiliá-los, os sujeitos relataram que as aplicações desenvolvidas complementam as aulas presenciais, diversificando os materiais de apoio, de forma que no Laboratório de Anatomia 3D estão disponíveis diferentes tecnologias que, integradas, auxiliam na apropriação do conhecimento de forma autônoma. Abaixo apresenta-se alguns extratos de análise que evidenciam essa postura:

"Creio que a utilização para aulas seria ótima, pois o aluno pode ficar em sua casa e aprender, caso ocorra alguma duvida pode pesquisar diretamente pela internet. Claro, não haverá aquele contado direto com alunos e professores, mas ainda assimé uma boa idéia." (sujeito 3 - aluno da disciplina de Anatomia)

"Apesar de eu não ser adepta a cursos a distância, acredito que seria bem útil este aplicativo para aulas em EAD, pois no ambiente encontramos vídeos, slides, sites importantes, animações, coisas que em aula presencial a gente não vê, pois temos as peças reais no laboratório. Então acho que poderia ser usado para dar aulas à distância para aqueles que precisam ou querem fazer a disciplina nessa modalidade. "(sujeito 1 - aluno da disciplina de Anatomia)

Em relação às aplicações desenvolvidas os extratos evidenciaram que a utilização das aplicações educacionais em 3D auxilia principalmente a materializar conteúdos abstratos, de forma a complementar o material de apoio utilizado em sala de aula que possuem apenas imagens estáticas:

"[...] complementam a matéria que já foi trabalhada em sala de aula. Podemos dizer que o Laboratório de Anatomia do Second Life tira a explicação passada em aula do abstrato e deixa concreto, sendo possível ver o conjunto (órgão), realizando suas funções. " (sujeito 2 aluno da disciplina de Anatomia)

Assim, concorda-se com Schimiguel et al.(2003 p. 236), quando afirma que as animações são importantes recursos para auxiliar nos processos de ensino e aprendizagem por materializar conteúdos dificeis de serem compreendidos, por serem 
complexos ou abstratos, e ainda por apresentar uma versão simplificada da realidade, focando os elementos mais importantes.

A respeito da avaliação da simulação e animação desenvolvidas, os sujeitos foram questionados se consideravam que estas poderiam auxiliar na construção do conhecimento para a disciplina de Anatomia, e se auxiliaram na resolução dos desafios propostos no ambiente. Conforme os extratos de análise a seguir, ficou evidenciado que a animação e a simulação facilitaram a resolução dos desafios propostos, sendo que os relatos que seguem são a respeito da simulação que reproduz o movimento das hemácias no interior da veia e da artéria:

"Claro que auxilia, pois se a pessoa não sabe ainda diferenciar uma artéria de uma veia, a animação mostra a diferença e talvez esclareça mais a atividade proposta. " (sujeito 1 aluno da disciplina de Anatomia)

"Sim, a visualização da espessura das camadas que formam os vasos e o movimento das hemácias dentro dos mesmos, dá noção clara das diferenças estruturais entre eles." (sujeito 5 - professor da disciplina de Anatomia)

Com relação à animação que reproduz os movimentos de sístole e diástole do coração, embora os sujeitos tenham relatado que a animação auxiliou na resolução dos desafios, relataram também ter encontrado dificuldades na resolução do desafio que solicitava a identificação de cada estrutura numerada. O motivo da dificuldade relatada pelos alunos se dá ao fato de que algumas das estruturas numeradas ainda não haviam sido trabalhadas em sala de aula, de forma que durante a avaliação das aplicações, o professor de Anatomia estava presente e os auxiliou na resolução desse desafio. Seguem alguns extratos de análise:

"Não só pode como auxiliou, só achei a imagem meio confusa em relação ao local das veias e artérias. A proposta é identificar as partes enumeradas, então se não tivesse uma representação com os números ninguém conseguiria fazer." (sujeito 2 - aluno da disciplina de Anatomia)

"Sim, pois o movimento em 3 dimensões dá uma percepção melhor para compreensão e auxilia o aluno a materializar o conteúdo abstrato (dúvida). Ex.: O aluno tem dificuldade em entender uma figura em 2 dimensões, pois perde ou não tem noção de profundidade." (sujeito 5 - professor da disciplina de Anatomia)

Sendo assim, concorda-se com Lévy (2005, p.67), quando aponta que as simulações "podem servir para testar fenômenos ou situações em todas as suas variações imagináveis, para pensar no conjunto de consequências e de implicações de uma hipótese, para conhecer melhor objetos ou sistemas complexos ou ainda para explorar universos fictícios de forma lúdica". Então as simulações, ao permitirem a representação dinâmica em três dimensões, facilitam a compreensão de conceitos complexos, pois permite visualização por diferentes ângulos, sendo possível perceber características que em imagens estáticas ficam comprometidas, como noção de profundidade e tamanho.

\section{Considerações Finais}

As experiências já realizadas com o Second Life nos ambientes educacionais demonstram o potencial de interação e imersão desse metaverso, pois ao possibilitar diversas formas de comunicação, apresenta-se como uma alternativa para minimizar a falta de presença física do professor. O Second Life permite uma sensação de presença, desperta o sentimento de estar em relação com o outro, aumentando o grau de envolvimento dos sujeitos envolvidos no ambiente, que pode contribuir para potencializar a experiência de aprendizagem. 
Constatou-se que a construção de aplicações educacionais em 3D com conteúdos interativos, através de animações e simulações, contribuem para otimizar os processos de ensino e aprendizagem relacionados aos conceitos da área de Anatomia. Em relação ao processo de aprendizagem do aluno, percebeu-se que a visualização das peças anatômicas em mais de uma dimensão auxilia a materializar conceitos abstratos, ampliando assim as possibilidades de compreensão de conceitos complexos de Anatomia, auxiliando-os na construção do conhecimento referente a esta área.

Em relação ao processo de ensino, verificou-se que através da integração das diferentes tecnologias da Web $2.0 \mathrm{com}$ as tecnologias da Web3D, é possível construir um ambiente diversificado, com mídias de variados formatos, acrescentando recursos pedagógicos mais flexíveis e personalizáveis, que permitem maior mediação pedagógica entre aluno-conteúdo/conceito, aluno-professor e aluno-aluno. Assim, percebe-se que o aluno mantém por mais tempo o interesse na realização das atividades/desafios propostos, na medida em que também constrói o seu próprio espaço de aprendizagem, deixando de ser apenas um receptor passivo de informação.

Através desse trabalho, espera-se ter colaborado com o desenvolvimento de aplicações educacionais em 3D que contribuam para a construção de novas metodologias com o uso dos metaversos-MDV3D, em especial para a área de Anatomia, que possam ser utilizadas tanto na educação presencial quanto na $\mathrm{EaD}$.

\section{Nota do Texto}

${ }^{1}$ Rede de Instituições Católicas de Ensino Superior. A Ilha RICESU é a representação do espaço digital virtual da RICESU no SL, composta por espaços comuns à Rede e por espaços destinados aos projetos específicos das instituições que a integram

${ }^{2}$ Teleduc e Moodle são sistemas de administração de atividades educacionais destinados à criação de comunidades on-line, em ambientes virtuais voltados para a aprendizagem.

${ }^{3}$ YouTube é um provedor gratuito de vídeos, permite que seus usuários carreguem e compartilhem vídeos em formato digital.

\section{Referências}

LÉVY, P. Cibercultura. São Paulo: Editora 34, 2005.

MATTAR, João. $O$ uso do Second Life como ambiente virtual de aprendizagem. In: IV SEMINÁRIO JOGOS ELETRÔNICOS, EDCAÇÃO E COMUNICAÇÃO CONSTRUINDO NOVAS TRILHAS. Salvador, 2008.

MATTAR, João; VALENTE, Carlos. Second Life e Web 2.0 na educação: o potencial revolucionário das novas tecnologias. São Paulo: Novatec, 2007.

SCHIMIGUEL, Juliano et al. Simulações como um recurso para a educação a distância - Conferência IADIS Ibero-Americana. Universidade Cruzeiro do Sul UNICSUL, 2003.

SCHLEMMER, Eliane et. al. Projeto de Pesquisa: Anatomia no metaverso Second Life: uma proposta em i-Learning. REDE DE INSTITUIÇÕES CATÓLICAS DE ENSINO SUPERIOR - RICESU. GPE-du UNISINOS/CNPq/RICESU. Universidade do Vale do Rio do Sinos - UNISINOS, 2010.

SCHLEMMER, Eliane; BACKES, Luciana. Metaverso: Novos espaços para a construção do conhecimento. In: Revista Diálogo Educacional - Programa de Pós Graduação em Educação da PUCPR. Curitiba, n.24 p.519-532, maio/ago 2008. 